RAJI CD21
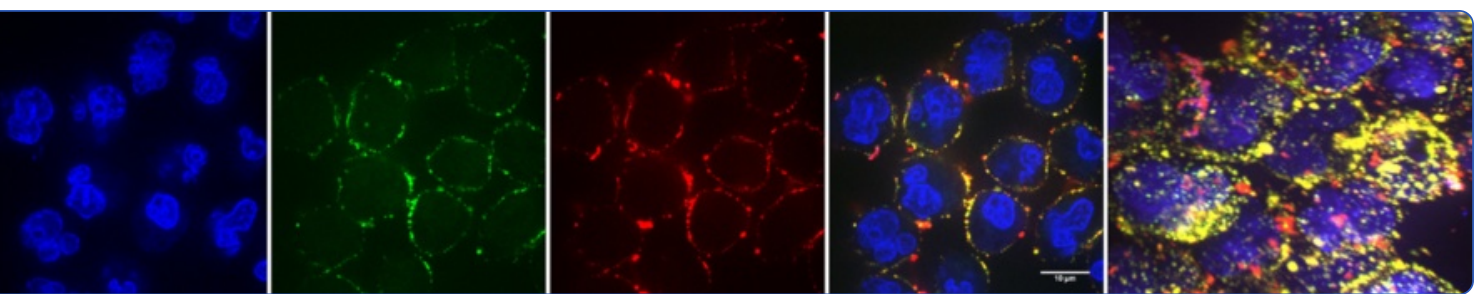

A chimeric EBV gp350/220-based VLP replicates the virion B-cell attachment mechanism and elicits long-lasting neutralizing antibodies in mice

Ogembo et al. 


\title{
A chimeric EBV gp350/220-based VLP replicates the virion B-cell attachment mechanism and elicits long-lasting neutralizing antibodies in mice
}

\author{
Javier Gordon Ogembo ${ }^{1}$, Matthew R Muraswki ${ }^{2}$, Lori W McGinnes ${ }^{3}$, Agapi Parcharidou², Rujapak Sutiwisesak', \\ Timelia Tison', Juan Avendano ${ }^{2}$, Deep Agnani ${ }^{2}$, Robert W Finberg ${ }^{1,4}$, Trudy G Morrison ${ }^{3,4}$ \\ and Joyce D Fingeroth ${ }^{1,2,4^{*}}$
}

\begin{abstract}
Epstein-Barr virus (EBV), an oncogenic gammaherpesvirus, causes acute infectious mononucleosis (AIM) and is linked to the development of several human malignancies. There is an urgent need for a vaccine that is safe, prevents infection and/or limits disease. Unique among human herpesviruses, glycoprotein (gp)350/220, which initiates EBV attachment to susceptible host cells, is the major ligand on the EBV envelope and is highly conserved. Interaction between gp350/220 and complement receptor type 2 (CR2)/CD21 and/or (CR1)/CD35 on B-cells is required for infection. Potent antibody responses to gp350/220 occur in animal models and humans. Thus, gp350/220 provides an attractive candidate for prophylactic subunit vaccine development. However, in a recent Phase II clinical trial immunization with soluble recombinant gp350 reduced the incidence of AIM, but did not prevent infection. Despite various attempts to produce an EBV vaccine, no vaccine is licensed. Herein we describe a sub-unit vaccine against EBV based on a novel Newcastle disease virus (NDV)-virus-like particle (VLP) platform consisting of EBVgp350/220 ectodomain fused to NDV-fusion (F) protein. The chimeric protein EBVgp350/220-F is incorporated into the membrane of a VLP composed of the NDV matrix and nucleoprotein. The particles resemble native EBV in diameter and shape and bind CD21 and CD35. Immunization of BALB/C mice with EBVgp350/220-F VLPs elicited strong, long-lasting neutralizing antibody responses when assessed in vitro. This chimeric VLP is predicted to provide a superior safety profile as it is efficiently produced in Chinese hamster ovary $(\mathrm{CHO})$ cells using a platform devoid of human nucleic acid and EBV-transforming genes.
\end{abstract}

Keywords: EBV, NDV, VLP, Vaccine, Neutralization

\section{Introduction}

Epstein-Barr virus (EBV) is an oncogenic human herpesvirus [1]. By adulthood, EBV has infected $>95 \%$ of the global population. Like all herpesviruses, EBV persists for life due to a complex life cycle consisting of alternate latent and lytic phases [1]. In the developing world, primary EBV infection typically occurs during early childhood and is asymptomatic. However, in malaria endemic regions childhood acquisition poses a heightened risk of

\footnotetext{
* Correspondence: joyce.fingeroth@umassmed.edu

${ }^{1}$ Department of Medicine, University of Massachusetts Medical School, 364

Plantation Street, LRB Room 323, Worcester, MA 01605, USA

${ }^{2}$ Department of Medicine, Beth Israel Deaconess Medical Center/Harvard

Medical School, Boston, MA, UK

Full list of author information is available at the end of the article
}

EBV+ Burkitt's lymphoma [1,2]. In high income countries primary infection is often delayed [2] resulting in a syndrome known as acute infectious mononucleosis (AIM) among 50-77\% of adolescents/young adults [3,4]. Although AIM is normally self-limited, illness can be prolonged. Catastrophic sequelae such as splenic rupture and hemophagocytosis may be life threatening, and AIM increases the risk of developing EBV+ Hodgkin lymphoma [1,2]. Consistent with its epithelial tropism, EBV is also highly associated with nasopharyngeal carcinoma and certain gastric and sporadic carcinomas [1]. Among healthy individuals, lytic EBV replication is limited and the pool of latently infected cells remains stable [5]. However, under conditions of immunosuppression, replication can accelerate, leading to expansion of EBV-infected cells. 
This increases the likelihood of de novo transformation of B-cells as seen in EBV+ post-transplant lymphoproliferative disorders (PTLD) and HIV-associated B-cell lymphomas [6,7]. Uninfected solid organ and stem cell transplant recipients are particularly susceptible to developing EBV+ PTLD in settings where preexisting EBV-specific immunity is lacking [8,9]. To date, disease management is suboptimal with frequent relapses and high treatment-related mortality.

Because of its oncogenic potential, options for developing safe prophylactic and/or therapeutic EBV vaccines have been limited. The recent success of subunit-based virus-like particle (VLP) vaccines targeting hepatitis B and human papillomavirus and their associated tumors $[10,11]$, suggests a similar strategy could prove successful for EBV. EBV is distinct from other herpesviruses, as a single antigen, glycoprotein (gp)350/220, is the predominant virion envelope protein $[1,12]$. Interactions between EBVgp350/220 and complement receptor type 2 (CR2)/ CD21 and/or (CR1)/CD35 on B-cells is required for cellular attachment and initiation of latent infection [13-15]. Therefore, gp350/220 is an attractive candidate for development of a prophylactic subunit vaccine.

Pre-existing antibodies provide a first line of defense against many viral pathogens. Much evidence indicates that neutralizing antibodies targeting gp350/220 are present in humans, prevent neonatal infection, and are readily generated in response to immunization of humans and other animals [16]. Nevertheless, in a Phase I/II clinical trial in young adults, vaccination with purified soluble recombinant gp350/220 did not prevent infection, although AIM was reduced [17]. While these observations indicate immunity to gp350/220 can limit clinical disease, the variable success of recombinant soluble protein trials underscore the historical observation that soluble protein vaccines are generally limited in immunogenicity [18] and do not elicit long-term protection. More physiologic presentation of gp350/220 to the immune system as would occur on exposure to repetitive units of gp350/220 mimicking the virion envelope, together with development of a vehicle such as a VLP with potential for recruiting innate immune cells [19] that robustly stimulate antibody production might achieve this goal.

In this study, we utilized a novel Newcastle disease virus (NDV)-based VLP as a delivery platform to display the gp350/220 ectodomain (ED) in particulate form. Typical VLPs assemble from one or more viral structural proteins forming repetitive arrays that resemble native virus - but usually lack viral nucleic acid [20]. Herein we report generation of a chimeric EBV-VLP based on gp350/220 and the NDV-fusion (F) protein (EBVgp350/ 220-F). These VLPs are distinct from recently described complex EBV-VLPs that require assembly in immortal human cell lines [21], may contain viral DNA/RNA and are inefficiently produced and released [22]. The chimeric EBVgp350/220-F VLPs are similar in diameter and shape to EBV virions and present repeated arrays of gp350/220 on a membranous surface. They are efficiently produced and released from non-human cell types such as Chinese hamster ovary (CHO), a Federal Drug Agency (FDA) approved vehicle. Immunization of BALB/c mice with EBVgp350/220-F VLPs without adjuvant elicited strong and long lasting neutralizing antibody responses able to block EBV infection in vitro.

\section{Materials and methods}

\section{Virus}

B95-8 strain EBfaV-GFP was provided by Richard Longnecker (Northwestern University, Chicago). EGFPEBV was prepared as described [23]. Kaposi's sarcoma herpesvirus (KSHV) and EBV-EGFP from the AGS line were gifts from Christine King (SUNY Upstate Medical School) and Liisa Selin (University of Massachusetts Medical School), respectively.

\section{Cell lines}

293A, a clone of 293 (human embryonic kidney) was from Life Science Technologies. 293 T, a 293 derivative expressing SV-40 $\mathrm{T}$ antigen, $\mathrm{CHO}$, Vero (African green monkey kidney), ELL-0 (chicken embryo), K562 (human erythroleukemia), Raji (EBV+ Burkitt's lymphoma), HB168 (72A1 murine hybridoma) were from the American Type Culture Collection. 293A, CHO, and ELL-0 were cultured in DMEM. Other lines were grown in RPMI media. All media contained 1\% L-glutamine, 10\% heat-inactivated fetal bovine serum (FBS) and $2 \%$ penicillin-streptomycin.

\section{Plasmid vectors}

Full length EBVgp350/220 (BLLF1) isolated from the BamHI L fragment of B95-8 [24] by PCR was cloned into pCAGGS [25]. An upstream primer containing a Sall restriction enzyme site and a Kozak sequence: Forward Primer: 5' - AAC ATA GCT GAC GCC ACC ATG GAG GCA GCC TTG CT -3 ' together with a downstream primer that incorporated a double stop followed by a NruI site: Reverse Primer: 5' - TTG ATA TCG CGA CTA TTA TTA TAC ATA GGT CTC GG -3' was used. After amplification, the PCR product was digested with SalI and NruI, purified and ligated into pCAGGS predigested with XhoI and MscI. Fidelity was confirmed by DNA sequencing.

\section{pCAGGS-EBVgp350/220-F}

A chimeric fragment consisting of nucleotides encoding gp350/220 ectodomain (ED), amino acids 1-864, fused to the NDV-F heptad repeat 2 (HR2), transmembrane (TM) and cytoplasmic (CT) domains, amino acids 466553, was constructed by three-way ligation (EBVgp350/ 
220-F). A PCR product containing the gp350/220 ED was digested with SalI and ScaI. A PCR fragment encoding the NDV-F membrane proximal HR2 domain, TM and $\mathrm{CT}$ domains in addition to adjacent pCAGGS vector sequences was PCR amplified from pCAGGS-F [26] incorporating a ScaI site upstream and a HindIII site downstream. Forward Primer: 5' - AAC ATA AGT ACT GCT TGG GAA TGT CAA CAA CTC G - 3 ' and Reverse Primer: 5' - TAC GCC AAG CTT GGG CTG CAG GTC GAG GGA TCT CCA -3'. This isolated F fragment was cut with ScaI and HindIII. The pCAGGS vector was digested with XhoI and HindIII and gel-purified. The three respective DNA fragments were co-incubated in a 5:5:1 ratio with T4 DNA ligase generating pCAGGSEBVgp350/220-F. Fidelity was confirmed by DNA sequencing. pCAGGS-F, pCAGGS-M and pCAGGS-NP derived from NDV (Avulavirus) have been described [26].

\section{Transfection, generation and purification of gp350/220-F VLPs}

$1.0 \mu \mathrm{g} /$ well of pCAGGS, pCAGGS-gp350/220 wildtype (WT) or pCAGGS-EBVgp350/220-F were individually transfected into $80 \%$ subconfluent $\mathrm{CHO}, 293 \mathrm{~A}$, Vero and ELL-0 cells seeded in six-well tissue culture plates using Lipofectamine and Reagent Plus (Life Sciences Technologies) according to the manufacturer's direction. Cells were harvested at $48 \mathrm{~h}$ post-transfection to assess surface expression of gp350/220 by cytometry.

Small-scale and large-scale VLP stocks were prepared as outlined [27]. For large-scale preparation, equal amounts $(8 \mu \mathrm{g} /$ plasmid $)$ of pCAGGS-NDV-M, -NP and pCAGGSEBVgp350/220-F plasmids were co-transfected into cells seeded in T-175 $\mathrm{cm}^{2}$ flasks. DNA-Lipofectamine complexes were incubated at $37^{\circ} \mathrm{C}$ for $5 \mathrm{~h}$ with $293 \mathrm{~T}$ and ELL0 or overnight with $\mathrm{CHO}$ cells. Complexes were removed by washing and $20 \mathrm{ml}$ of complete media was added. For some preparations $20 \mathrm{ml}$ of complete media containing $4 \mathrm{mM}$ of sodium butyrate (Millipore ED) and $20 \mathrm{ng} / \mathrm{ml}$ of TPA (12-O-tetradecanonylphorbol 13-acetate) (Sigma) was added as chemical induction had been reported to increase production of HIV VLPs [28], but the above addition did not significantly alter VLP yield in our hands. Eleven flasks were seeded for each large-scale preparation. VLPs were isolated by sedimentation and sucrose gradient purification [27].

\section{Antibodies}

Primary: Monoclonal antibodies (mAb)-72A1 and -2 L10 anti-gp350/220 were from EMD Millipore. Polyclonal rabbit anti-NDV and anti-HR2 have been described [29]. MAb anti-CD35 (clone E11) and anti-CD21 (clone LT21) were from BioLegend.

Secondary: Horseradish peroxidase (HRP)-conjugated goat anti-mouse IgG (total and isotype specific) antibodies or goat anti-rabbit antibodies for immunoblot or ELISA were from Sigma. Goat F(ab')2 anti-mouse IgG $(\mathrm{H}+\mathrm{L})$ AF488 or AF594 was used for cytometric and confocal analyses (Invitrogen). Goat anti-mouse IgG $(\mathrm{H}+\mathrm{L}) \mathrm{immu}-$ nogold was used for electron microscopy (EM) (Aurion).

\section{Biochemical analysis}

Purified EBV, VLPs or cells were lysed in RIPA buffer (Boston Bioproducts) containing a complete protease inhibitor cocktail (Roche Applied Science). Lysates were incubated for $15 \mathrm{~min}$ on ice, microcentrifuged for $5 \mathrm{~min}$ at 10,000 rpm and the protein content of each lysate determined by Bradford assay. Lysates were boiled for $5 \mathrm{~min}$ in Laemmli SDS-sample buffer (Boston Bioproducts) under non-reducing conditions. $10 \mu \mathrm{g}$ of lysate was loaded onto a $4-12 \%$ polyacrylamide gel for protein separation. Protein bands were detected by Pierce's silver stain kit according to the manufacturer's recommendation. For immunoblot, proteins were transferred to a PVDF membrane using iblot (Life Sciences Tech.). Membranes were blocked with 5\% non-fat dry milk (LabScientific) for $30 \mathrm{~min}$ and detected with specific antibodies as described in Results.

\section{Immunogold analysis (EM)}

VLPs and viruses were analyzed by EM as described [30]. Purified particles were dialyzed against $1 \mathrm{~L}$ of TNE (100 mM Tris; $2.0 \mathrm{M} \mathrm{NaCl} ; 10 \mathrm{mM}$ EDTA; $\mathrm{pH}$ 7.4) to remove residual sucrose, incubated with $3 \%$ bovine serum albumin (BSA) in TNE for $45 \mathrm{~min}$. and embedded on a grid. A 1:40 dilution of mAb-72A1 (10 ug/ml) in 1\% BSA/ TNE was added to the grid for $1 \mathrm{~h}$ at RT, washed and the grid re-incubated with gold-conjugated anti-mouse IgG for $1 \mathrm{~h}$. After two final washes, the grid was negatively stained with $12 \%$ phosphotungstic acid ( $\mathrm{pH} 7$ ) for $15 \mathrm{sec}$, air dried for $30 \mathrm{~min}$ and examined using a Tecnai transmission electron microscope (FEI).

\section{Binding assays, confocal microscopy and cytometry}

Confocal microscopy was performed as outlined [14]. $10^{6}$ cells seeded onto Labtek slides were incubated at RT for $1 \mathrm{~h}$ with uniform amounts of VLP pre-determined by silver stain and/or Bradford assay. Mixtures of cells and VLPs were first stained with anti-CD21, anti-CD35 or isotype control for $30 \mathrm{~min}$ on ice, washed $2 \mathrm{x}$ and reincubated with AF594-goat anti-mouse antibodies, washed and further stained with AF488-coupled-mAb-2 L10 for $30 \mathrm{~min}$ on ice. Nuclei were stained with DAPI 33342 (Sigma) for $5 \mathrm{~min}$ at RT. Cells were finally washed $2 \mathrm{x}$, mounted with Mounting Medium (DakoCytomation) and imaged with an UPlanApo 60x1.42 NA objective on an Olympus BX62 microscope fitted with a cooled Hamamatsu Orca AG CCD camera. Microscope, filters, and camera were operated as outlined [31]. Deconvolution was as described [14]. 
To analyze cell surface gp350/220 expression, cells transfected with relevant plasmids were suspended in PBS 2\% heat-inactivated FBS, washed twice with PBS, incubated with anti-gp350/220 (mAb-72A1), washed twice, re-incubated with goat anti-mouse-AF488 and rewashed. Cytometric analysis was performed on a FACScan or LSRII benchtop FC (Becton-Dickinson). Data were analyzed using CellQuest Pro Version 4.0.1 (B-D) and/or FlowJo Cytometry software (Tree Star Inc). A minimum 10,000 events was recorded for each analysis. Experiments were repeated $3 \mathrm{x}$.

\section{Immunization}

Groups of five 6-8 week BALB/c mice (Jackson Laboratories) were immunized intraperitoneally with $10 \mu \mathrm{g}$ EBVgp350/220-F VLP, soluble recombinant EBVgp350/220 ED protein (amino acids 4-863; Immune Technology) (positive control), or UV-inactivated EGFP-EBV (UV-EBV) (positive control). UV-inactivation was achieved by exposure to $254 \mathrm{~nm}$ UV light for $5 \mathrm{~min}$ (source model UVG-11, UVP) from a distance of $10 \mathrm{~cm}$, producing complete loss of EGFP expression upon EBV-superinfection of Raji (see below). Gp350/220 content of the respective immunogens was normalized by silver stain. Immunogens were resuspended to a final volume of $0.5 \mathrm{ml}$ in TNE 10\% sucrose or in $10 \%$ sucrose TNE buffer alone (vehicle control). Mice were boosted with equal amounts of antigen on days 43, 172, 183 and 218. After primary immunization, tail vein serum was obtained at two-week intervals until day 84, then again on days 154, 186, and 197. A terminal bleed was performed on day 228. Long-term antibody titers and neutralization were first assessed on day 56 to optimize the neutralization assay (data not shown). Thereafter neutralization was assessed with serum obtained at day 154 or 111 days after a single boost on day 43. Subsequently, three additional immunizations were administered on days 172, 183 and 218. All time points were used to determine anti-gp350/220 specific IgGs. Following the final boost mice were sacrificed on day 228 to again obtain sera for determination of anti-gp350/220 neutralization assays that followed a four-boost regimen. TNE served as a negative control. Experiments were repeated at least twice. Animal procedures were performed in accordance with the University of Massachusetts Medical School IACUC and Institutional Biosafety Committee.

\section{Enzyme-linked Immunosorbent Assay (ELISA)}

IgG titers were measured by ELISA [32] using soluble gp350/220 ED as target antigen. Briefly, 96-well microtiter plates (Nunc-Immuno Plate Maxisorp) were coated with $50 \mathrm{ng} /$ well of recombinant gp350/220 ED in a carbonate buffer ( $\mathrm{pH}$ 6.2) at $4^{\circ} \mathrm{C}$ overnight and blocked with $1 \%$ BSA. Serially diluted sera in PBS was added for $2 \mathrm{~h}$ at RT and washed. Antibody binding was detected with
HRP-labeled goat anti-mouse IgG, IgG1, IgG2a, IgG2b and IgG3 secondary antibodies at RT for $1 \mathrm{~h}$. Plates were washed $5 \mathrm{x}$ and the substrate tetramethylbenzidine (Life Science Technologies) was added. Reactions were stopped with $2 \mathrm{M}$ sulfuric acid. To determine antibody titer, optical density was read at $450 \mathrm{~nm}$ with an ELISA reader (Spectramax ${ }^{\circ}$ Plus 384, Molecular Devices). The highest antibody dilution yielding an $\mathrm{OD}_{450} 2 \mathrm{x}$ higher than that of TNE-treated mice was designated the endpoint titer. Anti-gp350/220 mAbs served as positive controls.

\section{Neutralization studies}

Day 154 sera from mice that had received a single booster on day 43 and day 228 sera (terminal) from mice serially immunized with EBVgp350/220-F VLP, UV-EBV, soluble gp350/220 ED and TNE were heat-inactivated at $56^{\circ} \mathrm{C}$ to remove complement. Sera were then diluted as described and then pre-incubated 1:1 with purified EGFPEBV at different concentrations (typically 5 or 10 microliters of a 1:5 virus dilution from a single frozen stock) for $1 \mathrm{~h}$ at RT before infecting $10^{5}$ Raji cells seeded in 24-well tissue culture plates as previously outlined [23,33]. Antigp350/220 mAb-72A1 (neutralizing), mAb-2 L10 (nonneutralizing) and sera from TNE-treated mice (vehicle) served as controls. Experiments were repeated at least 3 times. Plates were incubated at $37^{\circ} \mathrm{C}$ for 3 days and visualized daily to enumerate $\mathrm{GFP}^{+}$cells. Cytometry was performed on day 3 for end-point analysis.

\section{Statistical analysis}

Neutralization data were analyzed using Graph Pad Prism 6 Software (GraphPad Software, Inc., San Diego). The difference between neutralizing antibody titers of immunized and non-immunized (TNE-vehicle control) mice was determined using the unpaired two-tailed $t$ test for independent groups. Statistical significance of the tests was based on two-sided $\mathrm{p}$ values $\leq 0.05$.

\section{Results}

\section{Detection of chimeric EBV-gp350/220-F on the surface of} mammalian and avian cell lines

VLPs assemble from three or four virion proteins, the envelope glycoproteins, F (fusion, a type 1 glycoprotein) and/or HN (hemaglutinin-neuraminidase, a type 2 glycoprotein), together with core proteins $\mathrm{M}$ (matrix) and NP (nucleocapsid protein) that drive assembly and release $[27,34]$. Recently it was demonstrated that the ability to form VLPs is preserved when the ED of $F$ is substituted with an ED derived from unrelated viral envelope type 1 proteins as long as the $\mathrm{TM}$ and $\mathrm{CT}$ of $\mathrm{F}$ remain intact [35]. To generate EBVgp350/220 bearing VLPs, we first constructed an EBVgp350/220-F chimeric plasmid by fusing the nucleotide sequences encoding amino acids that comprise the entire ED of EBVgp350/220 to sequences 
encoding NDV-F HR2, TM and CT (Figure 1A). To assess whether the expressed chimera appropriately localized to the plasma membrane, pCAGGS-EBVgp350/220-F and pCAGGS-EBVgp350/220 WT plasmids were individually transfected into cell lines from four different species (CHO, ELL-0, Vero and 293A). Membrane expression of the gp350/220 ED was analyzed by cytometry. MAb-72A1 directed to the N-terminal attachment epitope of gp350/220 [36] detected expression of both gp350/220 WT and chimeric EBVgp350/220-F proteins at the surface of all relevant transfectants (Figure 1B). Anti-gp350/220 mAb-2 L10 [36] that recognizes a distinct epitope likewise detected gp350/220 surface expression (not shown). Comparative expression of WT gp350/220 and chimeric EBVgp350/220-F, within each transfected line, did not significantly differ. Gp350/220 was not detected in cells transfected with an empty pCAGGS vector (negative control).

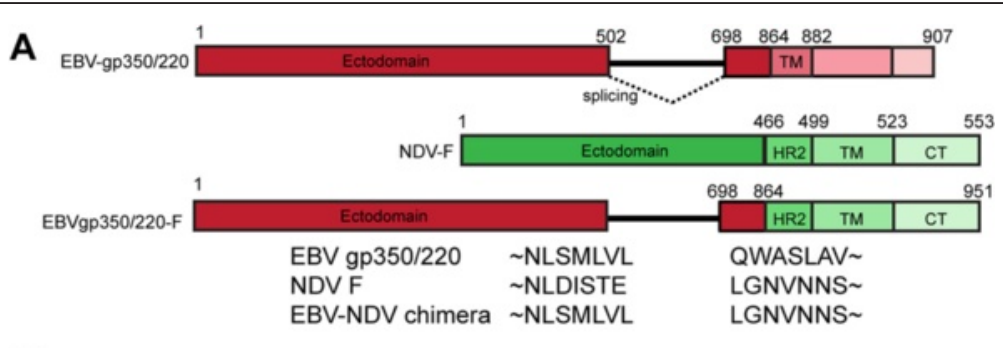

\section{B}

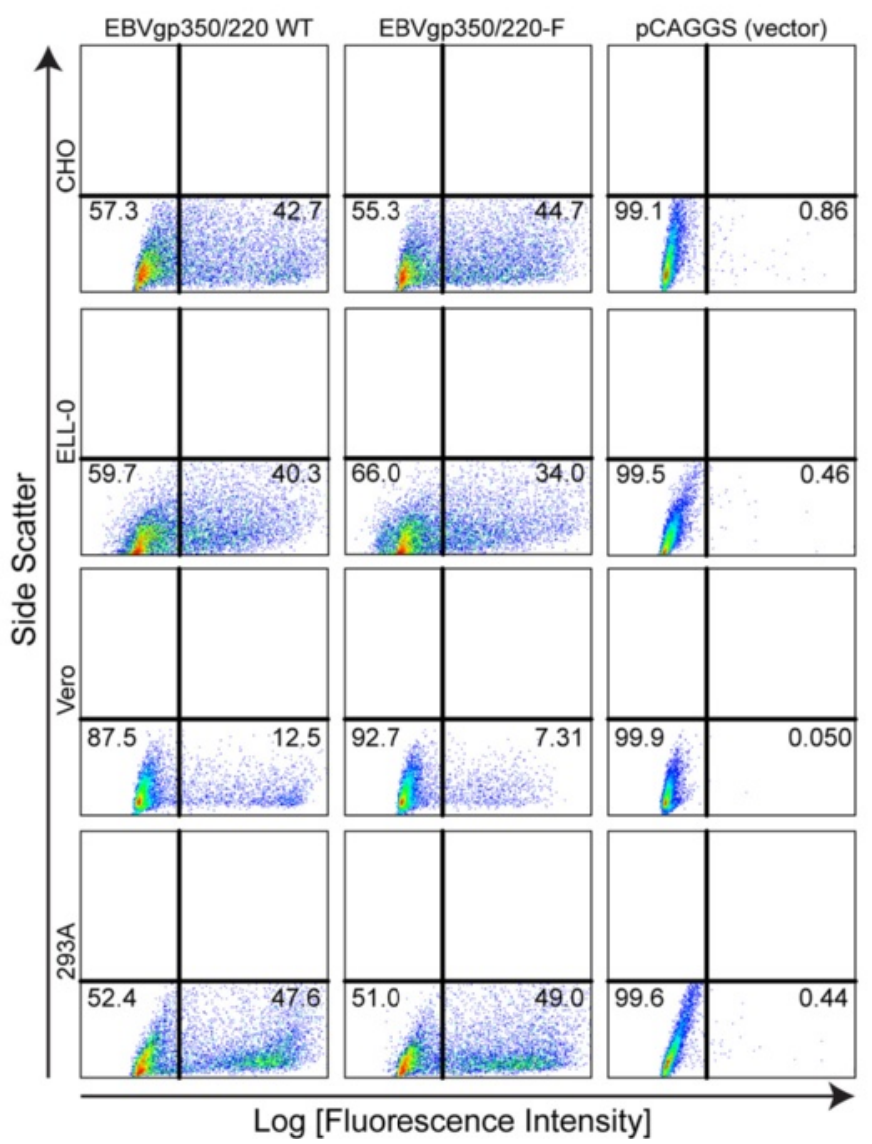

Figure 1 Construction and expression of EBVgp350/220-F chimeric protein. (A) Diagram of full length EBVgp350/220-WT (top), full length wild type NDV-F (middle), and chimeric EBVgp350/220-F (bottom) (not to scale). C-terminal amino acid sequences comprising the gp350/220 ectodomain (ED) and N-terminal sequences from NDV-F HR2 at the point of fusion are indicated. The bolded black line represents amino acid sequences deleted in frame in the gp220 isoform. Both isoforms contain the N-terminal B-cell attachment epitope. (B) Expression of EBVgp350/ 220-WT and EBVgp350/220-F on the surface of four cell lines (CHO, ELL-0, Vero and 293A). $10^{6}$ cells from each line were transfected with $1 \mu \mathrm{g}$ of pCAGGS-EBVgp350/220 WT, pCAGGS-EBVgp350/220-F or pCAGGS alone (vector control). At $72 \mathrm{~h}$ post-transfection, cells were stained with anti-gp350/220 mAb-72A1 followed by AF488-coupled goat anti-mouse $\lg G(H+\mathrm{L})$ and analyzed by flow cytometry. 


\section{Assembly and characterization of chimeric EBVgp350/ 220-F VLPs}

Following confirmation of plasma membrane expression, as required for particle assembly, pCAGGS-EBVgp350/ 220-F was co-transfected with NDV core proteins $M$ and NP into different cell lines to generate chimeric VLPs as diagramed in Figure 2A. Particles from distinct preparations released into cell supernatants were purified as outlined [27], lysed and protein analyzed by immunoblot using either anti-gp350/220 (mAb-72A1), polyclonal rabbit anti-NDV HR2 or anti-NDV (entire virus) (Figure $2 \mathrm{~B}$ ) for detection. To confirm the specificity of chimeric VLP formation and antibody recognition, a series of control experiments were performed to document

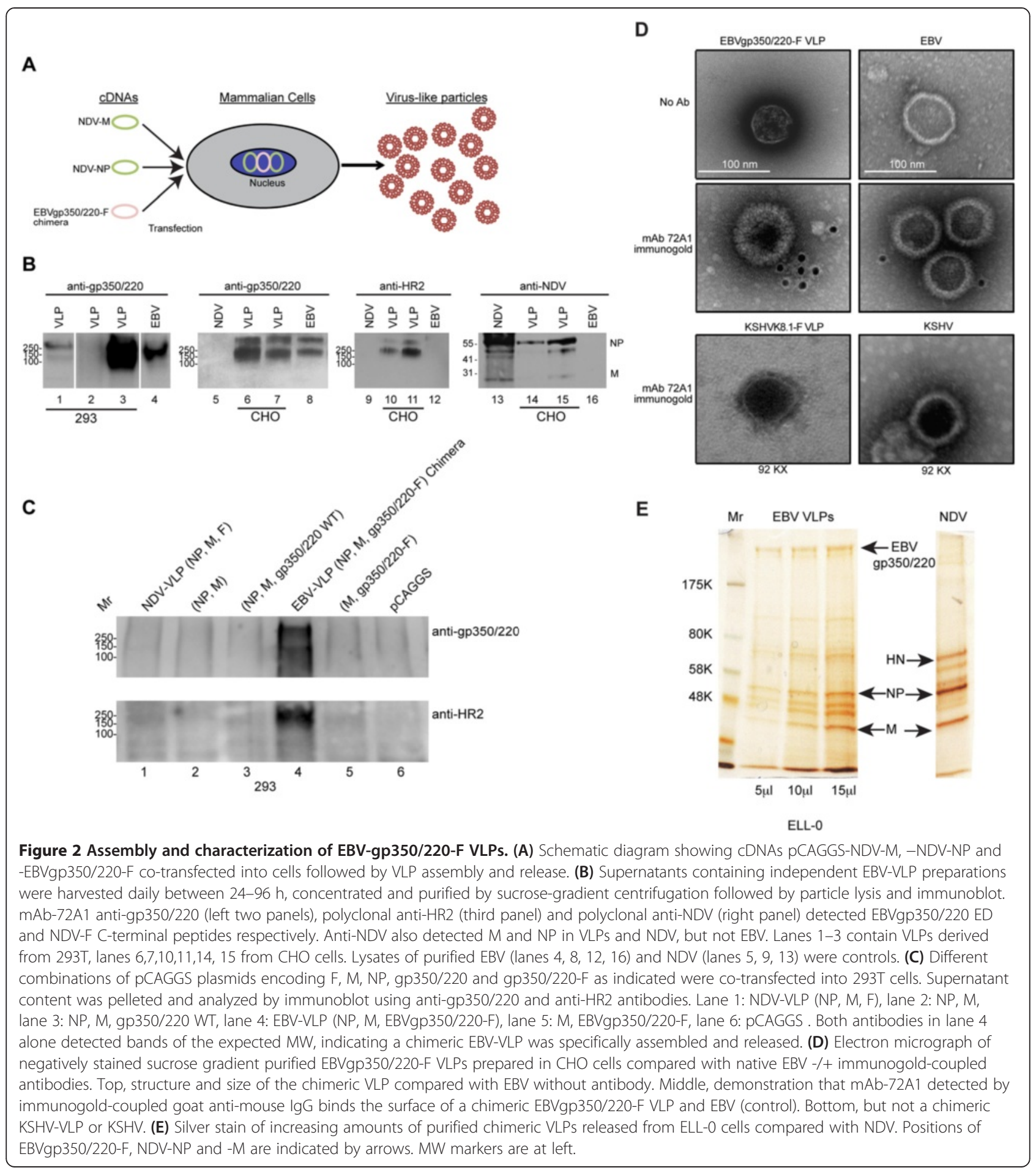


that classical requirements for NDV-VLP assembly were met. Different combinations of pCAGGS plasmids encoding NDV-F, -M, -NP, EBVgp350/220-WT, EBVgp350/220$\mathrm{F}$ as shown in Figure $2 \mathrm{C}$ were co-transfected into $293 \mathrm{~T}$ cells and the putative particles purified as previously described followed by immunoblot (Figure 2C). Chimeric VLPs expressing EBVgp350/220-F were detected with antigp350/220 (top panel) antibody only in cells co-transfected with EBVgp350/220-F, -M and -NP (lane 4), but not in cells transfected with F-M-NP (lane 1), M-NP (lane 2), EBVgp350/220-WT, -M-NP (lane 3), EBVgp350/220-F and -M (lane 5) or pCAGGS alone (lane 6). Anti-HR2 antibody detected the assembled chimeric VLP in lane 4 as well as a WT NDV-VLP in lane 1 (not shown) demonstrating that criteria for VLP formation were satisfied.

To further determine whether incorporation of EBVgp350/220-F into VLPs led to formation of particles similar in size and overall shape to the native virus, purified VLPs were compared to EBV by negative staining and immunogold-conjugated antibody analysis. Figure 2D top shows that purified VLPs containing EBVgp350/220-F were approximately $100 \mathrm{~nm}$ in diameter, similar to the diameter of typical EBV virion membranes, though they were less uniform in shape [37]. MAb antigp350/220 (72A1) detected with gold conjugated antimouse Ig bound the outer surface of both native EBV and the chimeric VLPs, indicating gp350/220 was expressed on the respective envelopes (Figure 2D, middle). Neither mAb-72A1 nor the gold-conjugated secondary antibody bound a KSHVK8.1-derived VLP (J.G.O. manuscript in preparation) or the KSHV envelope (Figure 2D, bottom) confirming the specificity of antibody recognition. The purity of the chimeric VLP compared with NDV and the uniformity of EBVgp350/220-F protein expression on chimeric VLPs was independently analyzed by silver stain (Figure 2E) alternatively revealing the content of these particles.

\section{Visualization of EBVgp350/220-F VLP attachment to CD21 and $\mathrm{CD} 35$ bearing cells}

EBVgp350/220 binds CD21 and/or CD35 on human cells $[13,14]$. To determine whether chimeric VLPs expressed from $\mathrm{CHO}$ cells retained the receptor-binding specificity of the virion envelope protein, we incubated EBVgp350/ 220-F VLPs with Raji, a latently EBV-infected B-cell line that naturally expresses high amounts of CD21 [13] and can be superinfected with EBV. In addition a panel of receptor negative cell lines, Nalm6 and K562 (not shown), together with their CD21 or CD35 transfectant sublines was investigated [14]. Receptors (red) and VLPs (green) were visualized by indirect immunofluorescence using a confocal microscope for detection. As shown in Figure 3, whereas chimeric VLPs abundantly bound Raji, no attachment to Nalm6 was detected. Nalm6CD21, Nalm6CD35,
K562CD21 and K562CD35 all bound EBVgp350/220-F VLPs. Moreover, in each of the receptor bearing sublines, the chimeric VLPs (green) co-localized (yellow) with the relevant cell surface receptor (Figure 4, two right columns).

\section{Development of specific lgG responses to EBVgp350/220 in BALB/c mice immunized with EBVgp350/220-F VLPs}

To determine whether chimeric VLPs elicit EBVgp350/ 220 specific antibody responses, mice were immunized intraperitoneally with $10 \mu \mathrm{g}$ of EBVgp350/220-F VLP derived from $\mathrm{CHO}$ cells. UV-EBV and soluble gp350/220 ED served as positive controls and TNE as vehicle control. Equivalence of gp350/220 protein content among the different immunogens was determined by silver stain (not shown). All animals received booster immunizations on days 43, 172, 183 and 218. Sera were collected two weeks post-boost. None of the animals displayed signs of local or systemic inflammation or changes in feeding or body weight that would indicate toxicity. Soluble recombinant gp350/220 ED served as the target antigen in an IgG ELISA (Methods). Anti-gp350/220 specific total IgG antibody titers significantly increased among mice immunized with the chimeric VLP, UV-EBV and soluble recombinant gp350/220 ED compared with pre-vaccination and control titers (Figure 4). Historical controls using NDV-F VLPs as immunogen were nonreactive in gp350/220-based ELISAs (not shown). The increase in EBV-gp350/220 specific antibody appeared to plateau on day 84 after the initial boost, but then further increased after the second and third boosts. There was a significant difference in antibody titers of mice immunized with UV-EBV, compared with soluble gp350/220 ED and EBVgp350/220-F VLP, although the slopes of the response curves were similar. Gp350/220 specific antibody was absent from TNE-immunized mice. All gp350/220-based immunogens produced long-term gp350/220-specific responses, though mice immunized with native EBV (UVEBV) maintained significantly higher titers of gp $350 / 220$ antibody compared to mice immunized with VLP or soluble recombinant protein.

\section{EBV-gp350/220 VLPs induce a dominant IgG1 subclass response}

To uncover the composition of IgG responses, we compared the subclass frequency of IgG antibodies induced by immunization with EBVgp350/220-F VLP, UV-EBV and recombinant soluble gp350/220 ED (Figure 5). IgG1 antibody, which typically reflects a T-helper type 2 response [38], was the most abundant subclass among mice irrespective of the gp350/220 immunogen. IgG1 responses uniformly increased over time when analyzed on days 14 , 56, 154 and 228 post-immunization (Figure 5A). In contrast, titers of IgG2a, IgG2b and IgG3 did not significantly 


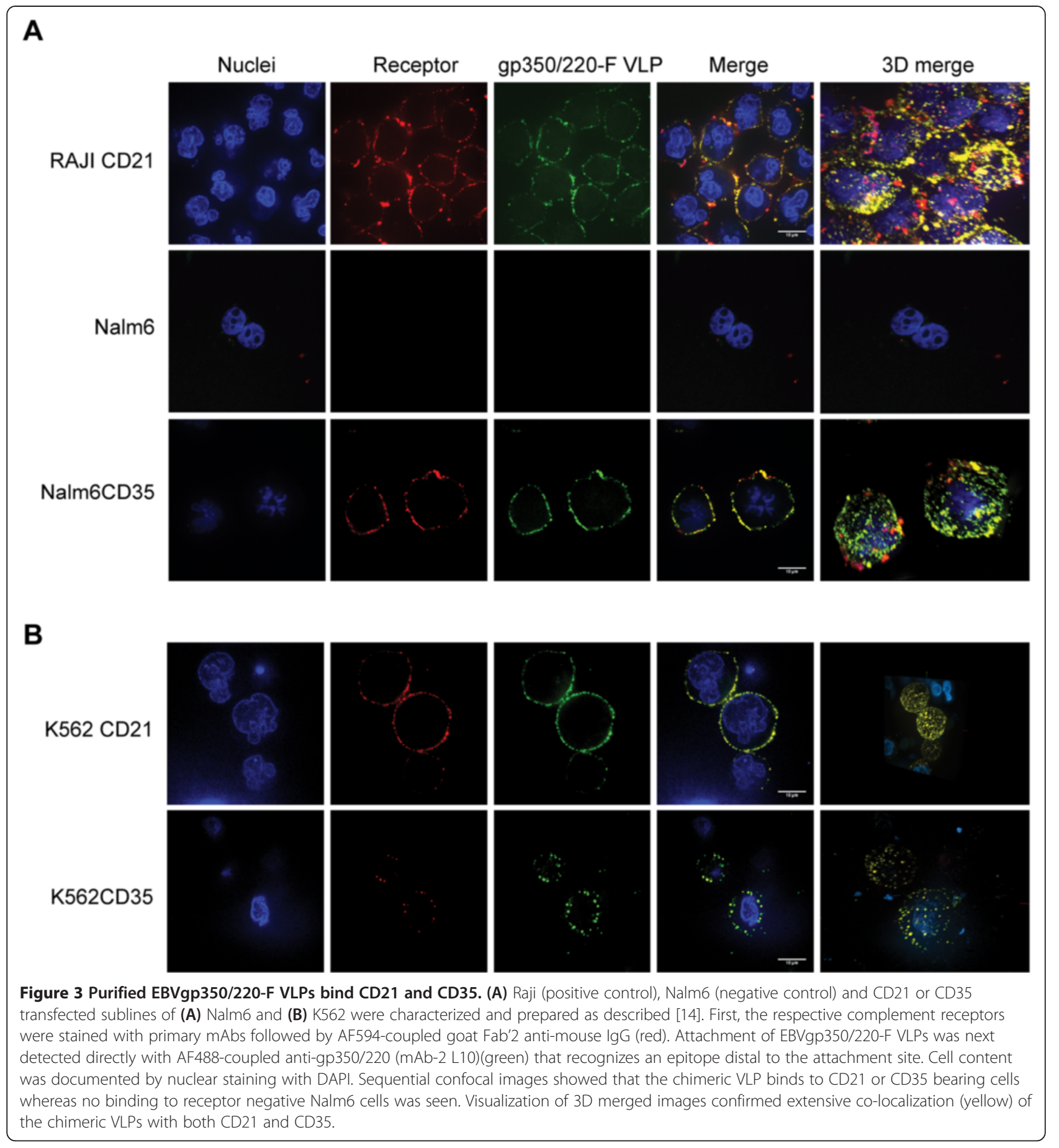

change or diminished over time. While IgG2a titers also appeared to trend upwards among mice immunized with UV-EBV (Figure 5B), (though to a 10-fold lesser degree than IgG1 titer) coordinate detection of IgG2a responses among the TNE-immunized control group in this assay alone (compare 5A, C, D) raised concern that the specificity of this reagent was compromised. A transient acute rise in IgG2b titers that accompanied primary chimeric VLP immunization did not persist.
Anti EBV-gp350/220 antibodies generated following VLP immunization neutralize EBV infection in vitro

It is well known that titer is not the sole gauge of a protective antibody response, as certain immunogens can induce antibodies that promote, rather than block infection and high affinity blocking antibodies can be highly effective at low titers [39]. To evaluate the ability of antibodies generated in response to chimeric EBV-VLP, UVEBV and soluble recombinant gp350/220 ED to block 


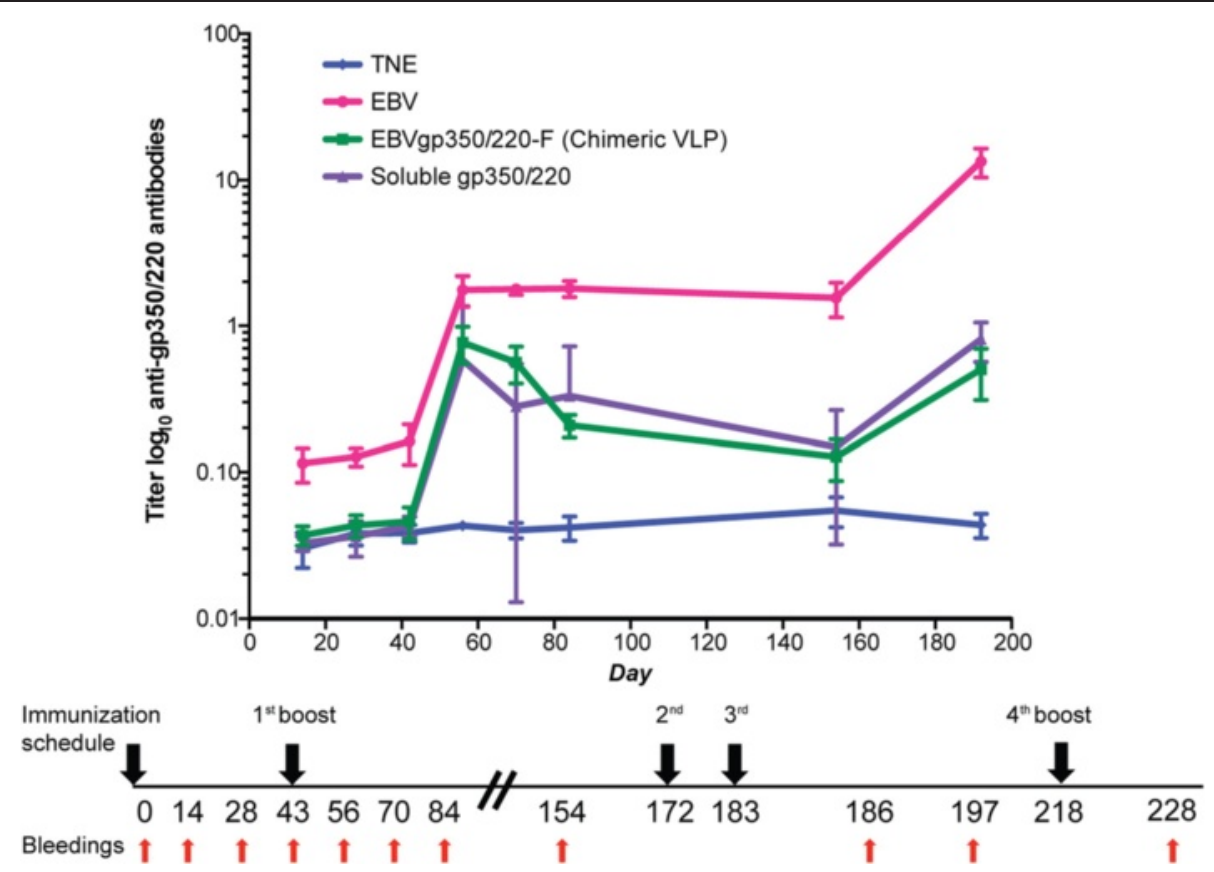

Figure 4 Long-term IgG anti-gp350/220 antibodies are generated in mice immunized with EBVgp350/220-F VLPs, UV-EBV and soluble recombinant gp350/220 ED. Groups of five mice were immunized intraperitoneally with either EBVgp350/220-F VLPS (green line), UV-EBV (red line) or soluble recombinant gp350/220 ED (purple line). Each immunogen contained equivalent amounts of gp350/220. TNE served as vehicle control (blue line). All immunizations were performed in the absence of adjuvant. Anti-gp350/220 lgG titers were determined over time up to day 228. Booster immunizations were performed on days 43, 172, 183 and 218 as indicated on the time line (bottom). Primary and booster vaccinations contained equivalent immunogen. Specific anti-gp350/220 ED titers were determined by ELISA (Methods). X-axis shows the day on which serum was obtained for ELISA. Y-axis displays anti-gp350/220 antibody titer on a log scale. Vertical lines indicate the average titer produced by groups of five mice at the time of serum collection and associated error bars indicate the standard deviation.

infection, we assessed the in vitro neutralizing antibody titers of sera collected (1) on day 154 (111 days after a single boost) and (2) on day 228 (terminal bleed collected 10 days after a fourth boost). Because EBV does not plaque and large virus quantities are difficult to obtain, EBV was first titered by the Raji cell infection assay (Figure 6A). Different amounts of a frozen stock of EGFP-EBV (0, 2.5, 5, 10 microliters) were incubated with Raji in the absence of serum. After infection with $10 \mu \mathrm{l}$ of stock EGFP-EBV ' $80 \%$ of Raji cells reproducibly fluoresced upon detection by cytometry whereas $5 \mu$ of stock EGFP-EBV reproducibly resulted in $\sim 50 \%$ fluorescence (Figure 6A). When $10 \mu \mathrm{l}$ EGFP-EBV was pre-incubated $1: 1$ with serial dilutions $(1: 3,1: 9,1: 27)$ of non-neutralizing mAb-2 L10 or TNE control sera fluorescence dropped to $\sim 50 \%$ of infected Raji cells (Figure $6 \mathrm{~B}$ ). In contrast when serially diluted sera from mice immunized with EBVgp350/220-F VLPs, UV-EBV or soluble recombinant gp350/220 ED was likewise pre-incubated with EGFP-EBV, infection was significantly reduced in a dose dependent manner compared to TNE-immunized sera (Figure 6B). Purified mAb-72A1 (positive control) containing only IgG1 antibody directed to the gp350/220 attachment epitope was most effective at neutralization.
Use of serial dilutions confirmed the specificity of the neutralizing antibody response.

In a second set of experiments neutralizing antibody was measured at the time of sacrifice ten days after a pre-terminal boost. When $5 \mu$ l EGFP-EBV was preincubated 1:1 with irrelevant mouse serum, further diluting virus, fluorescence dropped to $25 \%$ of infected Raji cells (not shown). As predicted, pre-incubation of EGFPEBV 1:1 with serum from TNE treated mice (negative control) produced $\sim 27 \%$ fluorescence of Raji (Figure $6 \mathrm{C}$ ) as did pre-treatment with the non-neutralizing antigp350/220 mAb-2 L10. In contrast when terminal sera from mice immunized with EBVgp350/220-F VLPs or UV-EBV was pre-incubated with EGFP-EBV, infection was reduced in comparison with TNE-immunized sera: $15 \%(\mathrm{p}=0.0217)$ and $5 \%$ fluorescent cells $(\mathrm{p}=0.0002)$ (Figure 6C) respectively. As expected, purified mAb-72A1 (positive control) was most effective at neutralization (1\% fluorescent cells, $\mathrm{p}=<0.0001$ compared with TNE). Antibodies generated after immunization with soluble recombinant gp350/220 ED were least effective (22\% fluorescent cells, $\mathrm{p}=0.0298$ versus TNE). Though the numbers are small, the comparative ability of antibodies generated in response to immunization with chimeric VLP versus UV- 


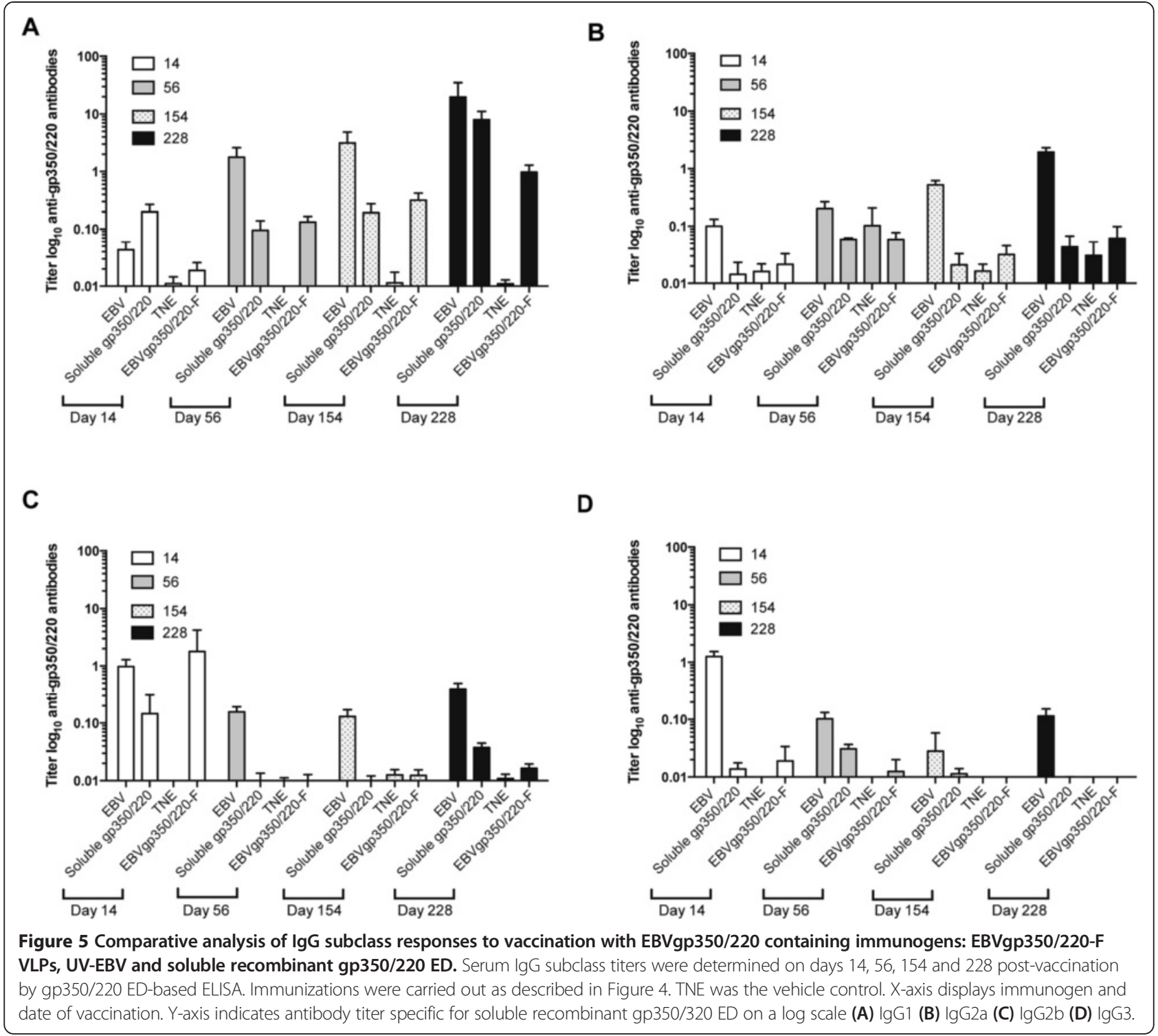

EBV to neutralize EBV infection of Raji cells was not significant $(\mathrm{p}=0.2188)$.

\section{Discussion}

Based on emerging evidence of the spectrum of EBVassociated diseases, Anthony Epstein first made a call for development of an EBV vaccine in 1976 [40]. To date, there is no licensed vaccine that prevents infection, AIM or any of the EBV-associated cancers. Because of the oncogenic potential of EBV, options for developing a safe, prophylactic and/or therapeutic EBV vaccine remain challenging. Similar to HSV1 replication defective vaccine candidates [41], EBV DNA packaging mutants [21] and disabled virions that lack the major oncoproteins [22] have appeal because of the multiplicity of potential immunogens present. However, incomplete knowledge of virion protein functions, concern about inadvertent association of oncogenic DNA/RNA fragments with assembled virions, limited production and release of virus, as well as current requirements for propagation in transformed human cell lines suggest such candidates may prove unable to meet stringent FDA safety guidelines. Additional concerns have been raised about EBV proteins expressed from replicating virus vectors such as Vaccinia or attenuated Measles [42] - the advantage and disadvantage being propagation of EBV-encoded nucleic acids and protein. Although vaccinia-based introduction of EBV vaccine targets, especially potential oncoproteins may be appropriate in patients with incurable tumors [43], current recombinant vaccinia vaccines are regarded as high risk because of frequent side effects even among healthy individuals. EBV capsids assembled from recombinant proteins expressed 


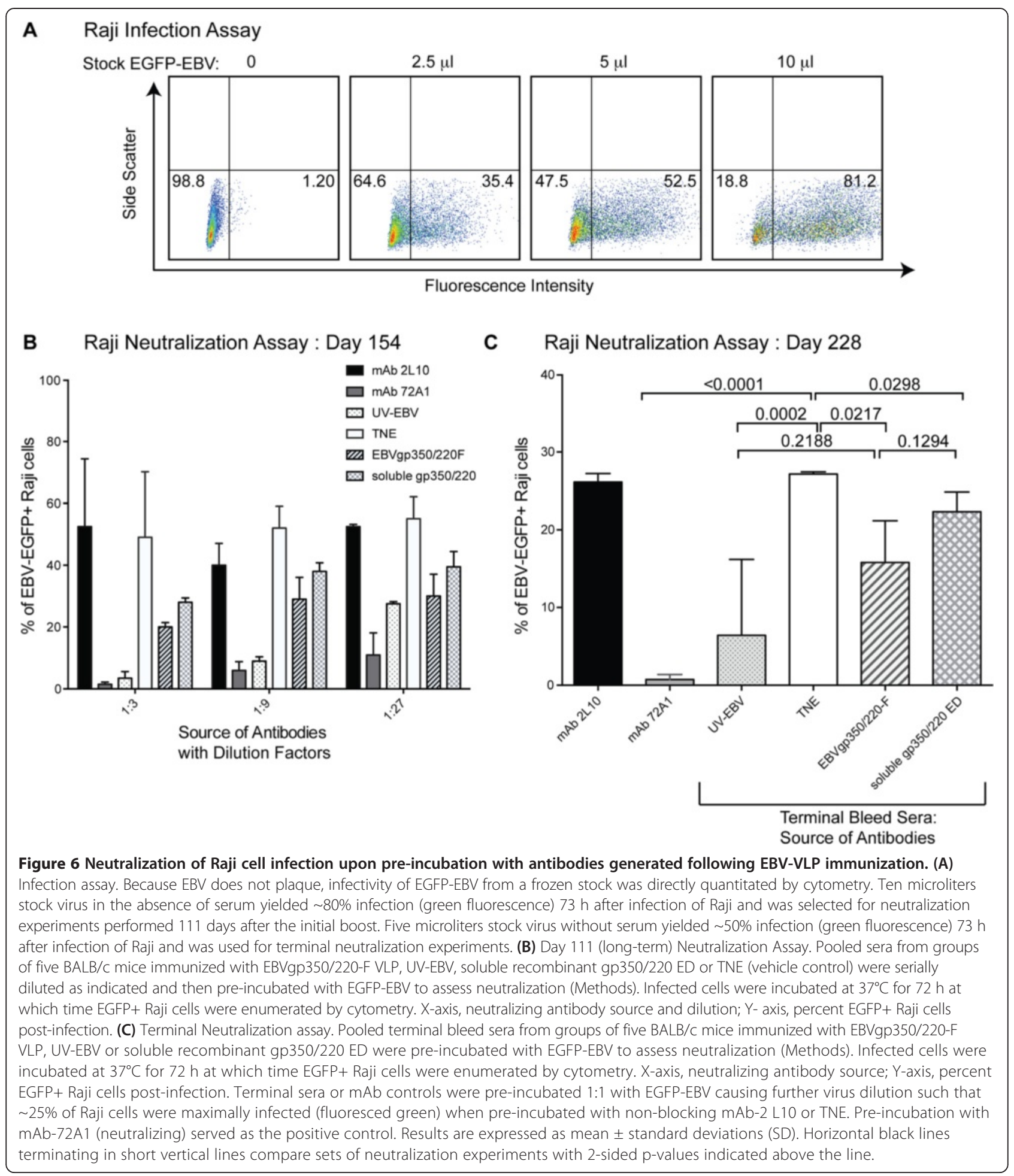

in insect cells have also been described as a potential vaccine candidate and would present repetitive antigen to the immune system [44]. However, at present their safety and their efficacy as neutralization targets remains to be documented.
EBVgp350/220 is the most abundant glycoprotein on the virus envelope and is the primary target of neutralizing antibodies following natural infection. Gp350/220 has long been a major focus of vaccine trials [16]. To date, vaccinia viruses expressing soluble recombinant 
gp350/220, attenuated measles virus expressing soluble recombinant gp350/220, truncated tetramers of the gp350/220 ED [45] as well as purified soluble gp350 protein have been evaluated to varying degrees either in animal models or in humans. However, controlled human Phase I/II clinical trials in which the immunogen was adequately characterized and in which efficacy could be statistically assessed remains limited. A three-dose regimen of purified soluble recombinant gp350 purified from $\mathrm{CHO}$ cell supernatants together with adjuvant was safe and immunogenic in healthy adults 18-25 years old residing in Europe [46], and in children scheduled for renal transplant [47]. Immunization induced gp350 specific neutralizing antibodies in the young adult group and provided protection from symptoms of AIM, however, EBV infection was not prevented [17]. The overall variable success of recombinant soluble protein trials underscores the historical observation that protein subunit vaccines generally display limited immunogenicity $[18,19]$, and are not optimal for eliciting long-term protection. We reasoned that more physiologic presentation of gp350/220 to the immune system as would occur on exposure to the repetitive units of gp350/220 displayed on the virion envelope might achieve robust protective humoral as well as cell-mediated responses.

In this study we described development of a candidate chimeric EBV VLP vaccine with the potential to satisfy safety requirements and overcome limited immunogenicity. The synthesis, assembly, biological properties and humoral immune responses to this immunogen were characterized. First we showed that following transfection of cDNA encoding the chimeric glycoprotein, the gp350/ 220 ED was well expressed on the surface of diverse cell lines including CHO, 293, Vero and ELL-0 (a prerequisite for VLP assembly). Next we documented that after cotransfection of relevant cDNAs, VLPs assembled and were efficiently released into $\mathrm{CHO}$ supernatants. Demonstration of production in $\mathrm{CHO}$ was significant, as over twothirds of recombinant therapeutic agents on the market are generated in $\mathrm{CHO}$ cell lines [48] that grow to high density in suspension and without FBS. Furthermore, no adventitious viral product, a major concern to regulatory authorities has been reported for $\mathrm{CHO}$ cells, in contrast to cell lines of human origin [49].

Subsequent analysis of the gradient purified chimeric VLPs by silver stain, immunoblot, and EM revealed that they were intact, pure and that the gp350/220 ED could be detected by distinct anti-gp350/220 mAbs. This suggested that the conformation of the attachment site was conserved and that some more distal portions of the ED were likely physiologically folded. The binding mechanisms used by native virus appeared to be retained as chimeric VLPs bound cells expressing the attachment receptors CD21 and CD35 and co-localized with each of these receptors. EM further revealed that chimeric VLPs resembled native EBV in their morphology and diameter, and immunogold staining revealed gp350/220 protein on the VLP surface.

EBV is a strictly human virus. Lack of an EBV vaccine is in part due to the paucity of robust in vivo models for studying EBV pathogenesis [50,51]. To begin to investigate the immunogenicity of EBVgp350/220-F VLPs, with a goal towards establishing efficacy in models such as humanized rodents, we immunized BALB/c mice with VLPs, UV-EBV or soluble recombinant gp350/220. No adjuvant was used in any of these experiments. We determined both the specific antibody titer and the ability of the antibodies to neutralize EBV infection in vitro. Total IgG anti-gp350/220 in sera of chimeric VLPs, UV-EBV and soluble recombinant gp350/220 slowly increased over time after primary immunization until day 43 at which time a first booster was administered. Following the boost, antibody titers rapidly rose among animals immunized with gp350/220 protein, peaking at day 56. No gp350/220 specific IgG antibody was detected in control mice (TNE). All anti-gp350/220 immunized mice developed long-term neutralizing antibody responses that were present 111 days after a single boost and were detected following additional boosts at the time of sacrifice on day 228 .

Although antibody titers and virus neutralization was highest among groups of mice immunized with UV-EBV compared to EBVgp350/220-F VLP, several factors may account for this observation and point to specific methods for optimizing chimeric VLP immunogenicity. Whereas the equivalence of total gp350/220 protein content was established in the three experimental groups prior to immunization, UV-EBV was less highly purified than the chimeric VLPs raising the possibility of low-level contamination with environmental adjuvants that enhanced antibody responses. The potential contribution of distinct adjuvants to VLP immunogenicity will be assessed in future experiments. A unique density or distribution of gp350 on the native virus particle may enhance its immunogenicity. Whereas UV-EBV (and the soluble recombinant protein) were produced in primate cells, the chimeric VLP was produced in rodent cells, thus contamination with xenogeneic antigen may have further contributed to the enhanced immunogenicity of UVEBV; and the soluble recombinant protein may de facto be less immunogenic than was scored herein. Furthermore antibody titers were detected using ELISA plates coated with primate (293-derived) recombinant gp350/ 220 - potentially amplifying the response of mice immunized with UV-virus and recombinant protein on this basis alone. We note that rather than enhancing immunogenicity as hypothesized, inclusion of the HR2 trimerization domain from NDV-F in the ED of the chimera may have contributed to some degree of misfolding and 
actually blunted the immune response to the chimeric VLP - this is currently being addressed. The quantity of gp350/220 ED expressed on the surface of VLPs can potentially be manipulated to introduce more immunogen in a more compact form that may enhance immunogenicity, or simple addition of more chimeric VLPs may enhance neutralizing antibody responses. Analogous to experiments conducted with respiratory syncytial virus [35] a further strength of this NDV platform is the potential to accommodate other EBV proteins able to block entry or initiation of infection upon introduction into a single VLP or by immunization with a combination of VLPs bearing different EBV chimeras, similar to VLP strategies that prevent human papillomavirus infection and associated cancers $[52,53]$.

\section{Conclusions}

While many acute viral infections and two major virusassociated malignancies have been reduced or eliminated through vaccination, adverse consequences resulting from EBV infection continue to emerge. Paradoxically, global development leading to delayed primary EBV infection has increased the incidence of AIM and with it a predisposition to Hodgkin lymphoma and autoimmune disease. In addition to prevention of EBV+ endemic malignancies, increasing survival of a spectrum of immunocompromised hosts susceptible to EBV+ lymphoproliferative diseases (e.g. the elderly, transplant recipients, persons with HIV or advanced autoimmune diseases) highlights a critical need for an effective immunogen - that is an EBV vaccine that is safe, prevents infection and/or limits the manifestations of disease. Herein we show that a simple innovative NDV-VLP platform supports generation of abundant chimeric EBVgp350/220-F VLPs devoid of oncogenic potential. These VLPs are efficiently produced, released, purified and quantified from $\mathrm{CHO}$ cells, a preferred repository for human biologics. The VLPs are nontoxic and stimulate production of long-lasting and neutralizing antibodies in standard BALB/c mice. Particle optimization and broad evaluation of immunologic properties in additional animal models merit ongoing investigation of this novel EBV vaccine candidate.

\section{Competing interests}

The authors declare that they have no competing interests.

\section{Authors' contributions \\ $M M, J O, J F, J A, D A, R S, T$ participated in the design and/or synthesis of fusion proteins and VLP production. LM, TM and RF provided expertise and reagents for production and analysis of VLPS. JO performed confocal and EM analysis. JO, RS, TT, TM, RF, JF designed, carried out and/or analyzed animal experiments. JF, JO, MM, TM conceived of the study and participated in its design and coordination. JGO and JF drafted and TM helped to draft the manuscript. All authors read and approved the final manuscript.}

\section{Acknowledgements}

We would like to thank Dr. Melanie Trombly for her assistance with design of the Figures. These studies were supported by an AHA Grant-in-Aid, NIH
R01Al063571, and a St. Baldrick's Foundation grant to JDF, by the UMASS Medical School Faculty Diversity Scholars Program and a NIH K01 CA18438801 to JGO and by NIH R56 Al093791 to TGM.

\section{Author details}

'Department of Medicine, University of Massachusetts Medical School, 364 Plantation Street, LRB Room 323, Worcester, MA 01605, USA. ²Department of Medicine, Beth Israel Deaconess Medical Center/Harvard Medical School, Boston, MA, UK. ${ }^{3}$ Department of Microbiology and Physiological Systems, University of Massachusetts Medical School, Worcester, MA, USA. ${ }^{4}$ Program in Immunology and Microbiology, University of Massachusetts Medical School, Worcester, MA, USA.

Received: 1 December 2014 Accepted: 20 January 2015

Published online: 06 February 2015

\section{References}

1. Rickinson AB, Kieff E. Epstein-Barr Virus. In: Knipe D, Howley P, editors. Fields Virology, vol. 2. 5th ed. Philadelphia: Lippincott Wilkins and Williams; 2007. p. 2680-700. Epstein-Barr Virus.

2. Hjalgrim $H$, Friborg J, Melbye M. The epidemiology of EBV and its association with malignant disease. Cambridge: Cmbridge University Press; 2007.

3. Balfour Jr HH, Odumade OA, Schmeling DO, Mullan BD, Ed JA, Knight JA, et al. Behavioral, virologic, and immunologic factors associated with acquisition and severity of primary Epstein-Barr virus infection in university students. J Infect Dis. 2013;207:80-8.

4. Luzuriaga K, Sullivan JL. Infectious mononucleosis. New England J Med. 2010;362:1993-2000.

5. Hochberg DR, Thorley-Lawson DA. Quantitative detection of viral gene expression in populations of Epstein-Barr virus-infected cells in vivo. Methods Mol Biol. 2005;292:39-56.

6. Carbone A, Vaccher E, Gloghini A, Pantanowitz L, Abayomi A, de Paoli P, et al. Diagnosis and management of lymphomas and other cancers in HIV-infected patients. Nat Rev Clin Oncol. 2014;11:223-38.

7. Gottschalk S, Rooney CM, Heslop HE. Post-transplant lymphoproliferative disorders. Annu Rev Med. 2005;56:29-44.

8. Allen UD, Farkas G, Hebert D, Weitzman S, Stephens D, Petric M, et al. Risk factors for post-transplant lymphoproliferative disorder in pediatric patients: a case-control study. Pediatr Transplant. 2005:9:450-5.

9. Paya C, Fung J, Nalesnik M, Kieff E, Green M, Gores G, et al. ASTS/ASTP EBV-PTLD Task Force and The Mayo Clinic Organized International Consensus Development Meeting: Epstein-Barr virus-induced posttransplant lymphoproliferative disorders. Transplantation. 1999;68:1517-25.

10. Schiller JT, Lowy DR. Vaccines to prevent infections by oncoviruses. Annu Rev Microbiol. 2010;64:23-41.

11. Kwak K, Yemelyanova A, Roden RB. Prevention of cancer by prophylactic human papillomavirus vaccines. Curr Opin Immunol. 2011;23:244-51.

12. Thorley-Lawson DA, Geilinger K. Monoclonal antibodies against the major glycoprotein (gp350/220) of Epstein-Barr virus neutralize infectivity. Proc Natl Acad Sci U S A. 1980;77:5307-11.

13. Fingeroth JD, Weis JJ, Tedder TF, Strominger JL, Biro PA, Fearon DT. Epstein-Barr virus receptor of human B lymphocytes is the C3d receptor CR2. Proc Natl Acad Sci U S A. 1984;81:4510-4.

14. Ogembo JG, Kannan L, Ghiran I, Nicholson-Weller A, Finberg RW, Tsokos GC, et al. Human complement receptor type 1/CD35 is an Epstein-Barr Virus receptor. Cell Rep. 2013;3:371-85.

15. Tanner J, Weis J, Fearon D, Whang Y, Kieff E. Epstein-Barr virus gp350/220 binding to the B lymphocyte $\mathrm{C} 3 \mathrm{~d}$ receptor mediates adsorption, capping, and endocytosis. Cell. 1987;50:203-13.

16. Cohen Jl, Fauci AS, Varmus H, Nabel GJ. Epstein-Barr virus: an important vaccine target for cancer prevention. Sci Transl Med. 2011;3:107fs107.

17. Sokal EM, Hoppenbrouwers $K$, Vandermeulen C, Moutschen M, Léonard P, Moreels A, et al. Recombinant gp350 vaccine for infectious mononucleosis: a phase 2, randomized, double-blind, placebo-controlled trial to evaluate the safety, immunogenicity, and efficacy of an Epstein-Barr virus vaccine in healthy young adults. J Infect Dis. 2007;196:1749-53.

18. Kingsman SM, Kingsman AJ. Polyvalent recombinant antigens: a new vaccine strategy. Vaccine. 1988;6:304-6.

19. Link A, Zabel F, Schnetzler Y, Titz A, Brombacher F, Bachmann MF. Innate immunity mediates follicular transport of particulate but not soluble protein antigen. J Immunol. 2012;188:3724-33. 
20. Chackerian B. Virus-like particles: flexible platforms for vaccine development. Expert Rev Vaccines. 2007;6:381-90.

21. Pavlova S, Feederle R, Gartner K, Fuchs W, Granzow H, Delecluse HJ. An Epstein-Barr virus mutant produces immunogenic defective particles devoid of viral DNA. J Virol. 2013;87:2011-22.

22. Ruiss R, Jochum S, Wanner G, Reisbach G, Hammerschmidt W, Zeidler R. A virus-like particle-based Epstein-Barr virus vaccine. J Virol. 2011;85:13105-13.

23. Speck $P$, Longnecker R. Epstein-Barr virus (EBV) infection visualized by EGFP expression demonstrates dependence on known mediators of EBV entry. Arch Virol. 1999;144:1123-37.

24. Biggin M, Farrell PJ, Barrell BG. Transcription and DNA sequence of the BamHI L fragment of B95-8 Epstein-Barr virus. EMBO J. 1984;3:1083-90.

25. Jun-ichi M, Satoshi T, Kimi A, Fumi T, Akira T, Kiyoshi T, et al. Expression vector system based on the chicken $\beta$-actin promoter directs efficient production of interleukin-5. Gene. 1989;79:269-77.

26. Pantua HD, McGinnes LW, Peeples ME, Morrison TG. Requirements for the assembly and release of Newcastle disease virus-like particles. J Virolol. 2006;80:11062-73.

27. McGinnes LW, Morrison TG. Newcastle disease virus-like particles: preparation, purification, quantification, and incorporation of foreign glycoproteins. Curr Protoc Microbiol. 2013;18.12:11-8. 12. 21.

28. Muratori C, D'Aloja P, Superti F, Tinari A, Sol-Foulon N, Sparacio S, et al. Generation and characterization of a stable cell population releasing fluorescent HIV-1-based Virus Like Particles in an inducible way. BMC Biotechnol. 2006;6:52.

29. McGinnes LW, Reitter JN, Gravel K, Morrison TG. Evidence for mixed membrane topology of the newcastle disease virus fusion protein. J Virolol. 2003;77:1951-63.

30. Battisti AJ, Meng G, Winkler DC, McGinnes LW, Plevka P, Steven AC, et al. Structure and assembly of a paramyxovirus matrix protein. Proc Natl Acad Sci. 2012;109:13996-4000

31. Ghiran I, Glodek AM, Weaver G, Klickstein LB, Nicholson-Weller A. Ligation of erythrocyte CR1 induces its clustering in complex with scaffolding protein FAP-1. Blood. 2008;112:3465-73.

32. Murawski MR, McGinnes LW, Finberg RW, Kurt-Jones EA, Massare MJ, Smith $G$, et al. Newcastle disease virus-like particles containing respiratory syncytial virus $\mathrm{G}$ protein induced protection in BALB/C mice, with no evidence of immunopathology. J Virol. 2010;84:1110-23.

33. Sashihara J, Burbelo PD, Savoldo B, Pierson TC, Cohen J. Human antibody titers to Epstein-Barr Virus (EBV) gp350 correlate with neutralization of infectivity better than antibody titers to EBV gp42 using a rapid flow cytometry-based EBV neutralization assay. Virology. 2009;391:249-56.

34. Pantua H, McGinnes LW, Leszyk J, Morrison TG. Characterization of an alternate form of Newcastle disease virus fusion protein. J Virol. 2005;79:11660-70.

35. McGinnes LW, Gravel KA, Finberg RW, Kurt-Jones EA, Massare MJ, Smith G, et al. Assembly and immunological properties of Newcastle disease virus-like particles containing the respiratory syncytial virus $F$ and $G$ proteins. J Virol. 2011;85:366-77.

36. Tanner J, Whang Y, Sample J, Sears A, Kieff E. Soluble gp350/220 and deletion mutant glycoproteins block Epstein-Barr virus adsorption to lymphocytes. J Virol. 1988;62:4452-64.

37. Germi R, Effantin G, Grossi L, Ruigrok RW, Morand P, Schoehn G. Three-dimensional structure of the Epstein-Barr virus capsid. J Gen Virol. 2012:93:1769-73.

38. Braun M, Jandus C, Maurer P, Hammann-Haenni A, Schwarz K, Bachmann MF, et al. Virus-like particles induce robust human T-helper cell responses. Eur J Immunol. 2012;42:330-40.

39. Civoli F, Kroenke MA, Reynhardt K, Zhuang Y, Kaliyaperumal A, Gupta S. Development and optimization of neutralizing antibody assays to monitor clinical immunogenicity. Bioanalysis. 2012;4:2725-35.

40. Epstein MA. Epstein-Barr virus-is it time to develop a vaccine program? J Natl Cancer Inst. 1976;56:697-700.

41. Dudek T, Knipe DM. Replication-defective viruses as vaccines and vaccine vectors. Virology. 2006;344:230-9.

42. Mok H, Cheng X, Xu Q, Zengel JR, Parhy B, Zhao J, et al. Evaluation of measles vaccine virus as a vector to deliver respiratory syncytial virus fusion protein or Epstein-Barr virus glycoprotein gp350. Open Virol J. 2012;6:12.

43. Taylor GS, Jia H, Harrington K, Lee LW, Turner J, Ladell K, et al. A recombinant modified vaccinia Ankara vaccine encoding Epstein-Barr Virus
(EBV) target antigens: a phase I trial in UK patients with EBV-positive cancer. Clin Cancer Res. 2014;20:5009-22.

44. Henson BW, Perkins EM, Cothran JE, Desai P. Self-assembly of Epstein-Barr virus capsids. J Virol. 2009:83:3877-90.

45. Cui X, Cao Z, Sen G, Chattopadhyay G, Fuller DH, Fuller JT, et al. A novel tetrameric gp350 1-470 as a potential Epstein-Barr virus vaccine. Vaccine. 2013;31:3039-45

46. Moutschen M, Leonard P, Sokal EM, Smets F, Haumont M, Mazzu P, et al. Phase I/II studies to evaluate safety and immunogenicity of a recombinant gp350 Epstein-Barr virus vaccine in healthy adults. Vaccine. 2007;25:4697-705

47. Rees L, Tizard EJ, Morgan AJ, Cubitt WD, Finerty S, Oyewole-Eletu TA, et al. A phase I trial of epstein-barr virus gp350 vaccine for children with chronic kidney disease awaiting transplantation. Transplantation. 2009;88:1025-9.

48. Walsh G. Biopharmaceutical benchmarks 2006. Nat Biotechnol. 2006;24:769-76.

49. Hesse F, Wagner R. Developments and improvements in the manufacturing of human therapeutics with mammalian cell cultures. Trends Biotechnol. 2000;18:173-80.

50. Chatterjee B, Leung CS, Münz C. Animal models of Epstein Barr virus infection. J Immunol Methods. 2014;410:80-7.

51. Yajima M, Imadome K, Nakagawa A, Watanabe S, Terashima K, Nakamura H, et al. A new humanized mouse model of Epstein-Barr virus infection that reproduces persistent infection, lymphoproliferative disorder, and cell-mediated and humoral immune responses. J Infect Dis. 2008;198:673-82.

52. Kirnbauer R, Booy F, Cheng N, Lowy DR, Schiller JT. Papillomavirus L1 major capsid protein self-assembles into virus-like particles that are highly immunogenic. Proc Natl Acad Sci U S A. 1992;89:12180-4.

53. Koutsky LA, Ault KA, Wheeler CM, Brown DR, Barr E, Alvarez FB, et al. A controlled trial of a human papillomavirus type 16 vaccine. $N$ Engl J Med. 2002;347:1645-51.

\section{Submit your next manuscript to BioMed Central and take full advantage of:}

- Convenient online submission

- Thorough peer review

- No space constraints or color figure charges

- Immediate publication on acceptance

- Inclusion in PubMed, CAS, Scopus and Google Scholar

- Research which is freely available for redistribution 